\title{
A patient with atrial septal defect with cyanosis with diagnostic dilemma turned out to be a case of Total Anomalous Pulmonary Venous Connection (TAPVC)
}

\author{
Mahbub Ahsan ${ }^{1}$, Md Lutfar Rahman², ASM shariful Islam³, Prokash Chandra Munshi", \\ Md Muzibur Rahman ${ }^{5}$, Md Mezanur Rahman ${ }^{6}$
}

\begin{abstract}
Total anomalous pulmonary venous connection (TAPVC) is a congenital cyanotic heart disease where all 4 pulmonary veins do not open directly to left atrium. There are 4 types of TAPVC. Supra cardiac type forms a confluence and may open to Innominate vein or SVC. Cardiac type usually opens to coronary sinus. Infracardiac type opens to hepatic veins or other veins. Mixed type is the combination of others. Of these 4 types infracardiac type is most vulnerable and presents with early features of cyanosis, pulmonary hypertension, pulmonary vein obstruction. We present the case of an 18 year old lady with atrial septal defect (ASD) with cyanosis. Pre operative echo showed ASD with 3rd chamber behind LA, CT angiogram revealed large ASD, with tongue like extended chamber in posteromedial aspect of $R A$. Preoperative angiogram report was inconclusive. Despite the diagnostic dilemma, we took the challenge and the patient went for open heart surgery. The patient recovered well and discharged on 10 th post operative day. Post operative echocardiogram is encouraging and she is doing fine.
\end{abstract}

Key words: Preterm, Prelabour, Rupture membrane, Feto-maternal, Outcome

Date of received: 07.09.2020

Date of acceptance: 20.05 .2021

DOI: https://doi.org/10.3329/kyamcj.v12i2.55445

KYAMC Journal.2021;12(02): 107-110.

\section{Introduction}

Total anomalous pulmonary venous connection (TAPVC) is a rare form of congenital anomaly in which all 4 pulmonary (PV) veins do not open directly to left atrium (LA). Its prevalence is 0.6-1.2/per 10000 live births, being one of the most common forms of congenital cyanotic heart disease. ${ }^{1,2}$ According to Darling and associates TAPVC is classified as supracardiac, cardiac, infracardiac and mixed variety. Majority of patient's presents with cyanosis, fatigue during feeding, poor weight gain, and diaphoresis. Maximum number of patients dies before 1 year of age without surgery. Even after surgery in hospital mortality was in the range of $2 \%$ to $18 \%$ after TAPVC repair. ${ }^{3,4}$
Pulmonary venous drainage stenosis occur in $6 \%$ to $9 \%$ of cases after surgery and particularly prevalent in young patient, infracardiac type, and preexisting pulmonary vein stenosis. ${ }^{5-7}$ Major independent risk factors are preexisting PV narrowing and pulmonary hypertension.

\section{Case report}

This 18 year old married female patient presented with exertional dyspnoea, palpitation, chest pain for 12 months. On examination, she was cyanosed, malnourished, systolic murmur in apical area, heart rate: 72/min, BP: $89 / 54 \mathrm{~mm}$ of $\mathrm{Hg}$. SPO2:88\%, weight: $30 \mathrm{~kg}$. CBC showed Hb: 9.5 gm/dl, HCT: 29\%, Platelet: 325000. Echocardiogram shows ASD (secundum), $3^{\text {rd }}$ chamber

1. Assistant professor, Department of Cardiovascular and thoracic surgery, Khwaja Yunus Ali Medical College and Hospital, Enayetpur, Sirajganj, Bangladesh.

2. Professor and HOD of Cardiovascular and thoracic Surgery, Khwaja Yunus Ali Medical College and Hospital, Enayetpur, Sirajganj, Bangladesh.

3. Assistant professor, Department of Cardiovascular and thoracic surgery, Khwaja Yunus Ali Medical College and Hospital, Enayetpur, Sirajganj, Bangladesh.

4. Senior Register, Department of Cardiovascular and Thoracic surgery, Khwaja Yunus Ali Medical College and Hospital, Enayetpur, Sirajganj, Bangladesh.

5. Professor and HOD of Anesthesia, Khwaja Yunus Ali Medical College and Hospital, Enayetpur, Sirajganj, Bangladesh.

6. Assistant professor, Department of cardiac anesthesia, Khwaja Yunus Ali Medical College and Hospital, Enayetpur, Sirajganj, Bangladesh.

Correspondence: Dr Mahbub Ahsan, Assistant professor, Department of Cardiovascular and thoracic Surgery, Khwaja Yunus Ali Medical College and Hospital, Enayetpur, Sirajganj, Bangladesh. Mobile No: +8801711174424. Email: Mahbub.ahsan8@gmail.com 
behind LA, dilated RA, RVand PA. Left to right shunt, pulmonary hypertension with TR grade II with PASP: $67 \mathrm{~mm}$ of $\mathrm{Hg}$ (Figure 1). CT shows large ASD (Figure 2), folded tongue like extended chamber at posteromedial aspect of RA in between and connecting both atrium, dilated RA, RV,PA and PV with Pulmonary hypertension (Figure 3). Cardiac catheterization revealed nothing contributory. Despite the diagnostic dilemma we decided to go for surgery. We found that, Innominate vein, SVC, RA, RV enlarged and dilated (Figure 4). All pulmonary veins open to a separate chamber that opens to coronary sinus. The coronary sinus was dilated (Figure 5). A 10x9 mm ASD II present. So, on table it was found to be a case of TAPVC intracardiac type. Under cardiopulmonary bypass, de roofing of coronary sinus done and pericardial patch was sewn to keep the all pulmonary veins in left side including the coronary sinus (Figure 6). Later Devega procedure was done to correct TR. Patient smoothly weaned from bypass and shifted to CICU with minimum inotropic support. She was extubated in the evening and discharged in $10^{\text {th }}$ post operative day in a stable condition (Figure 7). She came for follow up after 2 weeks and she is alright. Post operative Echo shows successful ASD closure, PASP $50 \mathrm{~mm}$ of $\mathrm{Hg}$, TR Gr1, and PH.

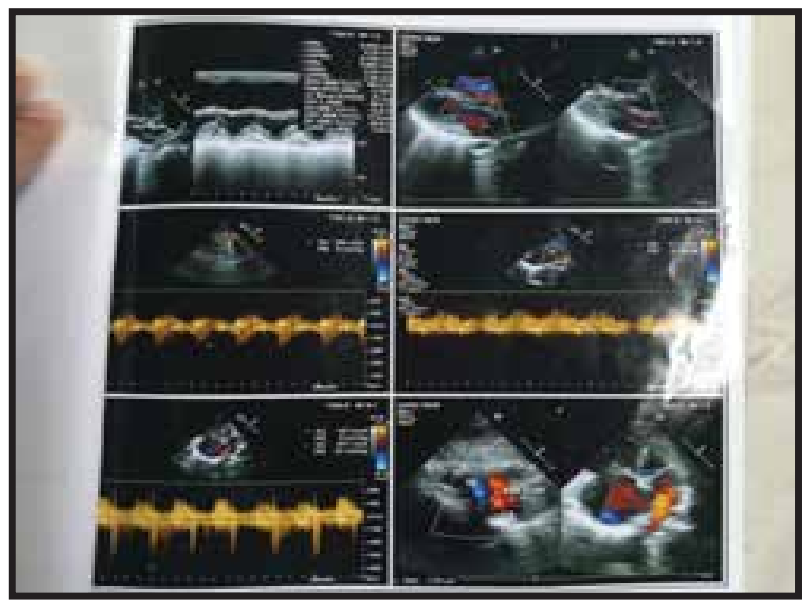

Figure 1: Pre operative Echo

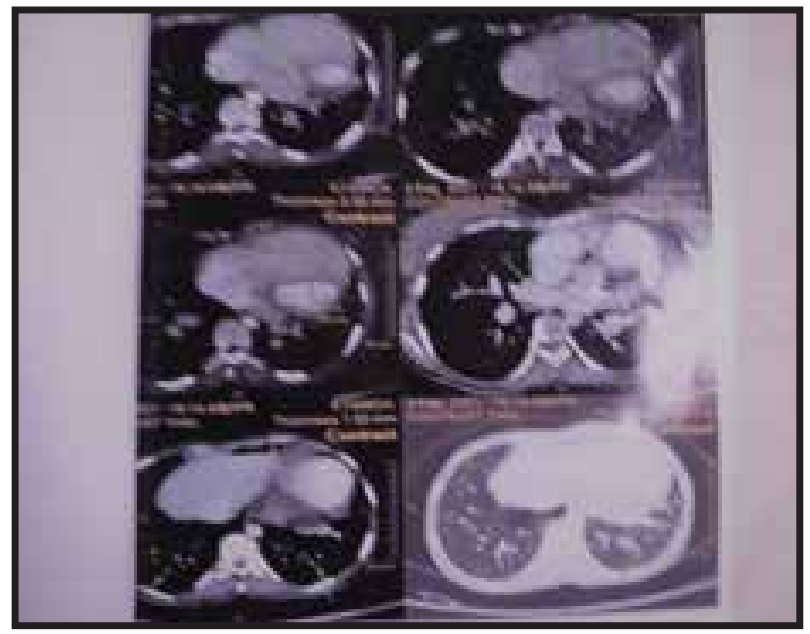

Figure 2: Pre operative CT scan

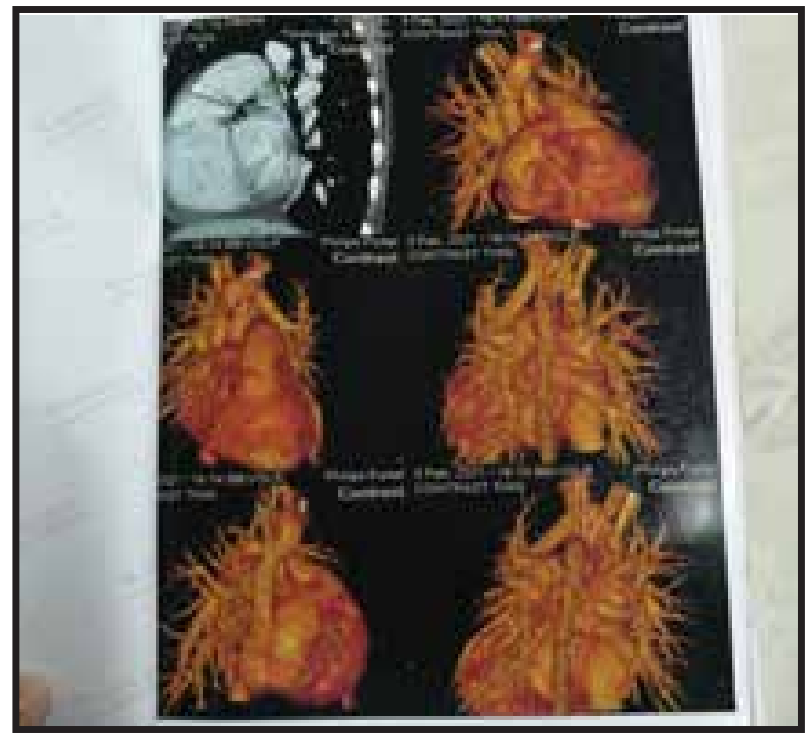

Figure 3: Pre operative CT scan

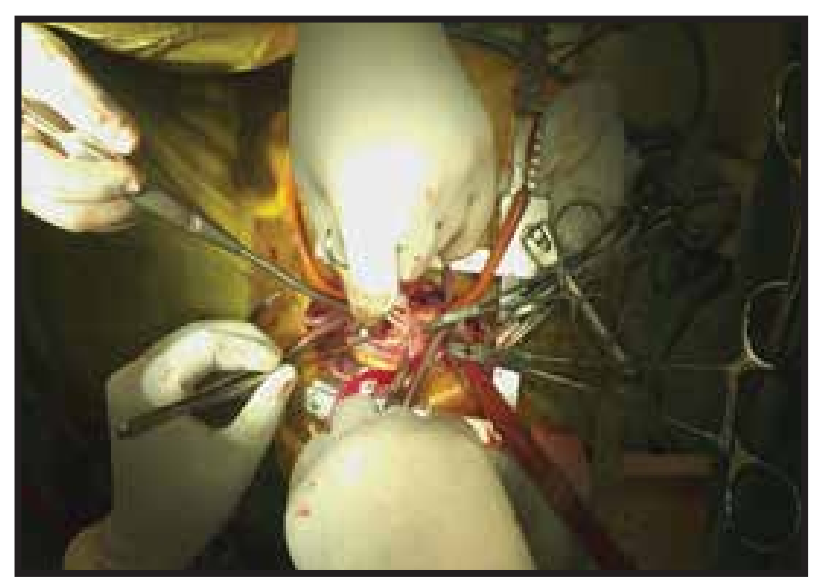

Figure 4: Per operative picture of the patient

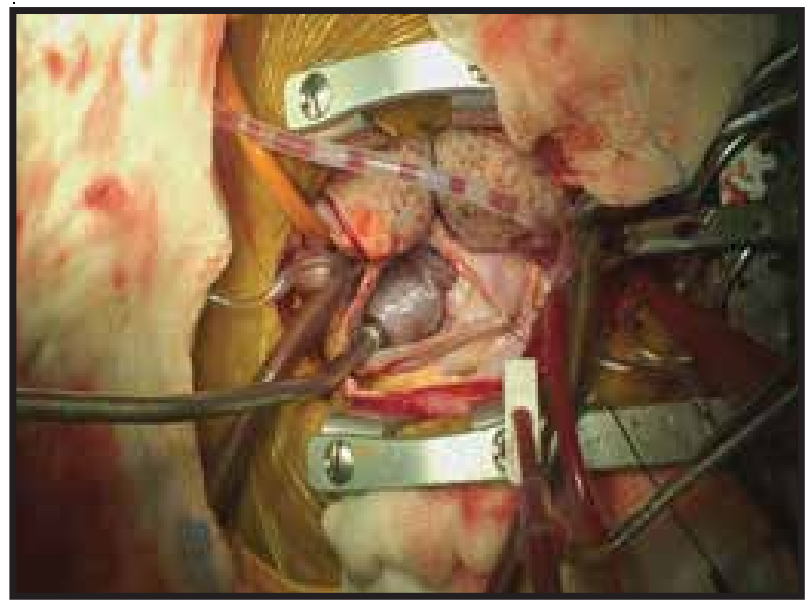

Figure 5: Per operative picture of the patient 


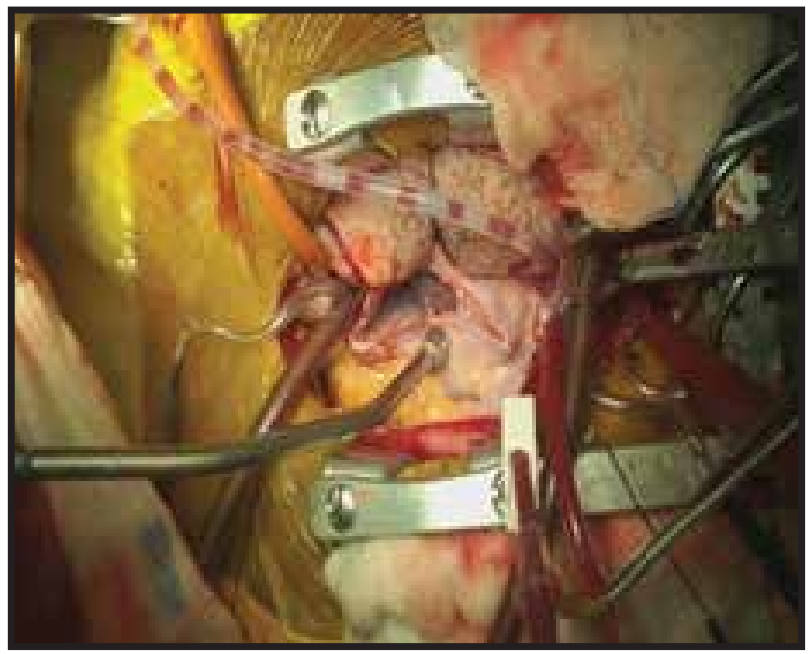

Figure 6: Per operative picture of the patient

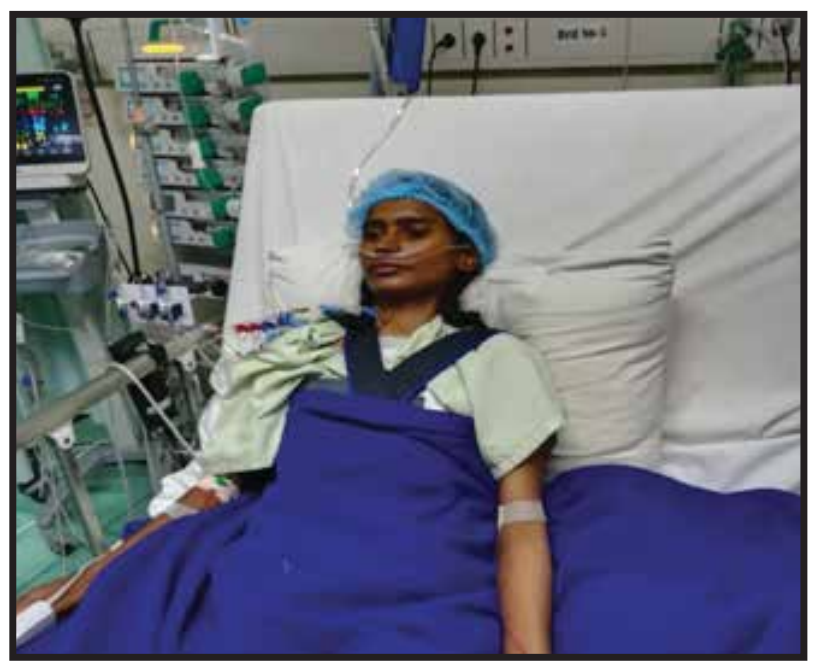

Figure 7: Post operative picture of patient in CICU

\section{Discussion}

Our patient presented with ASD with cyanosis. Preoperative Echocardiography and CT scan was not very conclusive. Despite the diagnostic dilemma, we took the challenge to go for open heart surgery and found that this was a case of TAPVC. Wilson $^{8}$ first described TAPVC in 1798. After that 4 types of TAPVC appeared after one and half centuries later. The pioneers in surgical treatment of TAPVC are Senning ${ }^{9}$ and Lewis and his coworkers ${ }^{10}$ who performed operation using closed method or an open approach with deep hypothermia and inflow occlusion technique respectively.

The study of Hellmut ${ }^{11}$ revealed supracardiac type (41\%), Cardiac (17\%), infracardiac type (36\%) and mixed type (6\%). $30 \%$ of TAPVC cases are associated with other heart disease such as Atrial septal defect (ASD) which is the main life line of blood flow to left atrium. Post operative complications include pulmonary venous obstruction (PVO), pulmonary hypertension, and right heart failure. $\mathrm{PVO}$ is calculated as $0=$ no stenosis (mean gradient $\leq 2 \mathrm{~mm}$ of $\mathrm{Hg}, 1=$ mild stenosis (mean gradient 2-6.9 $\mathrm{mm} \mathrm{Hg}$ ), $2=$ severe stenosis (mean gradient $\geq 7 \mathrm{~mm} \mathrm{Hg}$ ) and $3=$ complete occlusion.

Previous studies revealed that PVO might be present in $25 \%$ to $50 \%$ of TAPVC cases at initial diagnosis. ${ }^{12,13}$ Corrective surgery for TAPVC should be done as early as possible.

In the study of Hellmut ${ }^{11}$, patients with infracardiac type had higher pulmonary artery pressure and became symptomatic earlier. Obstructive forms are neonatal surgical emergencies that lead to death in the absence of surgical correction ${ }^{14}$, which is often difficult and must be negotiated with the anatomical types of TAPVC. ${ }^{15}$ Though previous studies showed low body weight, young age, prematurity were associated with higher mortality, but recent studies showed that these factors are not as great risk as before. ${ }^{6,17}$

In 2010, Bobby ${ }^{18}$ and associates applied a new technique which is known as sutureless technique. In this process large incisions are made over the pulmonary veins and pericardium is used in situ to create neo left atrium. There is no suture line on the native pulmonary vein tissue. The term sutureless means there is no direct communication between pulmonary vein and left atrium. The advantage is less intimal proliferation because the suture line is not directly over pulmonary vein and secondly there is less chance of narrowing or distortion of pulmonary veins. It has been shown that sutureless technique improves survival in post operative pulmonary vein stenosis (PVS) ${ }^{19}$.

\section{Conclusion}

Total anomalous pulmonary venous connection (TAPVC) though uncommon, should be treated as soon as possible. Because of danger of high mortality within first year, surgical correction is the only alternative. Post operative morbidity and mortality has been reduced significantly in recent past because of advancement of surgical knowledge and surgical technique.

\section{Acknowledgement}

We are thankful to our OT staff and CICU staff for their excellent support and encouragement.

\section{References}

1. Reller MD, Sticklandf MJ,, Riehle- Colarusso T, Mahle WT, Correa A. A prevalence of congenital heart defects in metropolitan Atlanta, 1998-2005. J Pediatr. 2008;153:807-813.

2. Seale AN, Uemura H, Webber SA. Total anomalous pulmonary venous connection-morphology and outcomes from an international population based study. Circulation 2010; 122: $2718-2726$.

3. Kelle AM, Backer CL, Gosett JG, Kaushal S. Total anomalous pulmonary venous connection: results of surgical repair of 100 patients at a single institution. J Thorac cardiovasc Surg 2010; 139: 1387-1394. 
4. Lamb RK, Quareshi SA, Wilkinson JL, Arnold j, west CR Hamilton DI. Total anomalous pulmonary venous drainage: seventeen -year surgical experience. JThorac Cardiovasc Surg. 1998; 96:368-375.

5. Caldarone CA, Najm HK, Kadletz M, Smallhorn JF. Freedom RM. Relentless pulmonary Vein stenosis after repair of total anomalous pulmonary venous drainage. Ann Thorac Surg 1998; 66; 1514-1520.

6. Sano S, Brawn WJ, Mee RB. Total anomalous pulmonary venous drainage. J Thorac Cadiovasc Surg 1989; 97: 886-892.

7. Wilson WRjr, Ilbawi MN, Deleon SY, Quinones JA. Technical modifications for improved results in total anomalous pulmonary venous drainage. J Thorac Cardiovasc Surg 1992; 103: 861-870.

8. Wilson J: On a very unusual formation of the human heart. Philos trans R Soc lond 1798; 88:33.

9. Senning A: Complete correction of total anomalous pulmonary venous return. Ann Surg1958; 148:99

10. Lewis J, Varco RL, taufic M, Niazi SA: Direct vision repair of triatrial heart and total anomalous pulmonary venous drainage. Surg Gynecol Obstet 1956; 102:713.

11. Oelert Hellmut, Schafers HJ, Stegmann T. Kallfetz HC. Complete correction of total anomalous pulmonary venous drainage: experience with 53 patients. Ann thorac Surg 1986; 41; 392-394.

12. Kelle AM, Backer CL $<$ Gossett JG, Kaushal S. Total anomalous pulmonary venous connection: results of surgical repair of 100 patients in a single institution. J Thorac Cardiovasc Surg 2010; 139: 1387-1394.
13. Hyde JA, Stumper O, Barth MJ. Total anomalous pulmonary venous connection : outcome of surgical correction and management of recurrent venous obstruction. Eur J Cardiothorac Surg 1999; 15: 735-741.

14. Jinghao Z, Botao G, Zhiwei X, Jinfeng L. The research on operation of obstructed total anomalous pulmonary venous connection in neonates. Scientific World Journal2014; 2014: 5765-5769.

15. Kirshborn P, Jaggers J, Underland R. Total anomalous pulmonary venous connection. Paediatric cardiac surgery 2003; 612-615.

16. Reardon MJ, Cooley DA, Kubrusly L. Total anomalous pulmonary venous return: report of 201 patients treated surgically. Tex Heart Inst J 1985; 12:131-141.

17. Morales DLS, Braud BE, Booth JH. Heterotaxy patients with total anomalous pulmonary venous return: improving surgical results. Ann Thorac Surg 2006; 82: 1621-1628.

18. Yanagawa B, Abdullah A,Dragulescu A, Viola N. Primary sutureless repair for simple total anomalous pulmonary venous connection: midterm results in a single institution. The J of Thorac \& Cardiovasc Surg2011.

19. Najim HK, Caldarone CA,Smallhorn J, Coles JG. A sutureless technique for the relief of pulmonary vein stenosis with the use of in situ pericardium. J Thorac Cardiovasc Surg. 1998;115: 468-470. 